\title{
An Evaluation of the Psychometric Properties of the Graduate Advising Survey for Doctoral Students
}

\author{
Benita J. Barnes \\ University of Massachusetts, \\ Amherst, MA, USA \\ barnesbj@educ.umass.edu
}

Edward W. Wolfe

Pearson, Iowa City, IA, USA

Ed.wolfe@pearson.com

\author{
Linda A. Chard \\ Independent Consultant \\ The Villages, FL, USA \\ linda.chard@yahoo.com
}

\author{
Martha L.A. Stassen \\ University of Massachusetts, \\ Amherst, MA, USA \\ mstassen@acad.umass.edu
}

\author{
Elizabeth A. Williams \\ University of Massachusetts, Amherst, MA, USA \\ Williams@educ.umass.edu
}

\begin{abstract}
Material published as part of this publication, either on-line or in print, is copyrighted by the Informing Science Institute. Permission to make digital or paper copy of part or all of these works for personal or classroom use is granted without fee provided that the copies are not made or distributed for profit or commercial advantage AND that copies 1) bear this notice in full and 2) give the full citation on the first page. It is permissible to abstract these works so long as credit is given. To copy in all other cases or to republish or to post on a server or to redistribute to lists requires specific permission and payment of a fee. Contact Publisher@InformingScience.org to request redistribution permission.
\end{abstract}

Graduate advisors are reputed to be the most important persons that a graduate student will interact with during his/her graduate training. However, research indicates that some graduate students are not satisfied with the quality of their advising experiences. As a result, there has been national interest in understanding the nature and quality of graduate students' advising experiences. In this study the dimensional structure, psychometric properties, and differential item functioning of the Graduate Student Advising Survey that measured various aspects of the advising experiences of master's and doctoral students from across various disciplines were examined. Specifically, we applied a multidimensional Rasch Model for the purpose of exploring the dimensional structure and documenting the item quality, and we examined the probability of matched groups endorsing items differently. The results indicate that a six-factor model, as opposed to any other model, more appropriately explained the data. Based on the findings, the authors determined that the instrument produces reliable measures that were relatively consistent across demographic groups.

Keywords: Doctoral Advising, Survey Instrument, Psychometric Properties, DIF

\section{Introduction}

At one time, graduate training in the United States (U.S.) was hailed as one of the best systems of doctoral education in the world (Golde, 2006; Nettles \& Millet, 2006). However, with vexing 
problems, such as a declining interest by American students going on for doctoral study, longtime to degree, high attrition rates (Ehrenber \& Kuh, 2009), and disparate advising and mentoring experiences of doctoral students (Austin, 2002; Fagan \& Suedkamp Wells, 2004), it is now questionable whether graduate education in the U.S. will continue to be able to produce the best and brightest researchers necessary to maintain a competitive edge in a global knowledge economy (Denecke, Frasier, \& Redd, 2009). Therefore, much thought has been given to the ways in which graduate education, in general, and doctoral education, in particular, may need to be reformed (Walker, Golde, Jones, Bueschel, \& Hutchings, 2008) in the $21^{\text {st }}$ century.

In particular, the way in which doctoral students are trained is one thorny aspect of graduate education that has come under increasing scrutiny (Walker et al., 2008). The apprenticeship modelwhere a doctoral student works one-on-one with a faculty member as an apprentice-is a defining characteristic of doctoral education in the U.S. Cornon (2008) observed that in good masterapprentice relationships, the master (advisor/supervisor) serves as teacher, mentor, cheerleader, and advocate. He indicates that when these relationships work well they can last a lifetime. Conversely, when the master-apprentice or advisor-advisee relationship does not work, it can be horrid (Walker et al., 2008) and produce many negative consequences for the advisee (Minor, 2003).

Due to the critical, yet unpredictable, nature of the advisor-advisee relationship, doctoral advising has garnered much research in recent years (Barnes, 2010; Barnes \& Austin, 2009; Barnes, Williams, \& Archer, 2010; Knox, Schlosser, Pruitt, \& Hill, 2006). Increasingly, quantitative survey research has been conducted that has built an empirically-based body of knowledge about doctoral students and their academic and advising experiences (see for example, Fagan \& Suedkamp Wells, 2004; Golde \& Dore, 2001; Nettles \& Millet, 2006).

What is missing, however, are surveys that are designed to generate knowledge about doctoral advising experiences within specific institutions. This gap is particularly significant given recent calls for graduate programs and departments to conduct their own assessments of graduate training and advising (Walker et al., 2008). Therefore, this study is designed to narrow this gap by analyzing the psychometric properties of an instrument that was developed at one large research university. The survey was designed to capture some of the key aspects of the doctoral advising experience that have been described in previous studies as critical to the advisor-advisee relationship. The advisor-advisee term is a U.S. based term. In other countries in the world advisors are called supervisors. The following review of literature identifies key themes in advising literature that provide a broader context for understanding the content of the survey items being examined in this study.

\section{Related Literature}

Generally speaking, the doctoral advisor is thought to be one of the most important people whom a doctoral student will interact with during her/his graduate degree program (Baird, 1995; Etzkowitz, Kemelgor, \& Uzzi, 2000; Hartnett \& Katz, 1977; Lovitts, 2001, 2004; Nettles \& Millet, 2006). The importance of the doctoral advisor to the advisee stems from the amount of influence the advisor has on multiple aspects of the doctoral degree process. For example, Lovitts (2001, 2004) stated that the advisor impacts the nature and quality of the students' experiences, the socialization processes, and postgraduate options and opportunities. Holland's (1998) research suggested that doctoral advisors play a significant role in the academic life and satisfaction of their doctoral advisees. Cheatham and Phelps (1995) concluded that doctoral advisors provide academic support, as well as provide opportunities for participation for professional growth and development. Lyons, Scroggins, and Rule (1990) argued that advisors help their advisees to develop habits of mind inclusive to the discipline as well as bolster their students' confidence through encouragement and praise. 
Despite the importance of the advisor-advisee relationship on graduate students' success, some students have reported their relationship with their advisor as being one of the most disappointing aspects of their graduate experience (Hartnett \& Katz, 1977). Jacks, Chubin, Porter, and Connolly (1983) found that 44\% of "all but dissertation" (ABD) students in their study cited poor relations with their advisor as one of the primary reasons why they did not complete their degrees. Similarly, Golde $(1998,2000)$ concluded that a mismatch between advisor and advisee is a leading cause of doctoral attrition. Others have cited murder and suicide (Hinchey \& Kimmel, 2000) as extreme but detrimental consequences of a poor advisor-advisee relationship.

Other studies on advising have sought to identify the functions or the roles of faculty advisors during the graduate degree process (Barnes \& Austin, 2009; McLure, 1989; Winston \& Polkosnik, 1984). Winston and Polkosnik (1984) contend that there are several essential roles and functions that doctoral degree advisors must fulfill if they are going to be successful in their advising. These roles include reliable information source, departmental socializer, advocate, role model, and occupational socializer. McLure (1989), building off the work of Winston and Polokosnik, identified four primary roles that both degree completers and non-completers desired from their faculty advisors. These roles included: a role model, a red tape cutter, an encourager, and a reliable source of information.

Examining the advisor-advisee relationship from the advisors' perspective, Barnes and Austin (2009) identified four primary functions their participants felt they performed: collaborator, mentor, advocator, and chastiser. Knox et al. (2006) also examined the role of the doctoral advisor from the advisors' perspective. The primary roles they found their participants performed included: serving as students' mentors and role models, addressing their advisees' professional goals, and tailoring the advising relationship to meet the needs of the advisee.

Several national studies have also examined critical components of doctoral students' experiences, which have included the advising experience. Golde and Dore (2001) conducted a study that included 27 institutions, 11 arts and sciences disciplines, and 4,000 respondents. The intent of their study was to gain insight into how doctoral students perceive their graduate education, particularly as it relates to the purpose, the content, and the various processes that are part and parcel to the doctoral school experience. Findings from Golde and Dore's (2001) study suggest that advising is a critical aspect of the doctoral experience and that how doctoral students are paired with their advisor is critical to their success. In addition, they found that doctoral students generally do not understand the process of doctoral education. Students reported that they do not have a clear understanding of certain aspects of the doctoral degree process such as advisor expectations.

The National Association of Graduate-Professional Students (NAGPS) (Fagen \& Suedkamp Wells, 2004) also conducted a large scale study in North America that sought to understand students' experiences during their graduate degree. The NAGPS study included over 32,000 doctoral students and recent graduates. Findings from this study suggest that graduate students are satisfied with their graduate school experience in general and would recommend their program to others. Similar to the Golde and Dore (2001) study, the NAGPS study revealed that the advisoradvisee relationship is critical to doctoral students' success and that a small number of respondents were not satisfied with the type of mentoring they received from their advisors.

The literature on graduate education firmly establishes the significant influences advisors have on their advisees' professional growth and academic success. The literature also provides evidence that severe consequences can result when advisor-advisee relationships go awry. Due to the cost and consequences associated with poor advising, understanding the quality of the doctoral experiences, particularly around advising and related issues, becomes critical for institutions, and policy makers to assess. However, it is equally critical to assess the quality of those instruments that are being developed and used to ensure that the surveys themselves are accurately and reliably meas- 
uring the construct(s) they are intending to measure. The purpose of this study is to provide a comprehensive examination of the psychometric properties of the Graduate Student Advising Survey (GSAS) that was used at a university in the Northeast region in the U.S. in an effort to learn more about the quality of the GSAS in measuring graduate students' - at the master's and doctoral level - advising experiences. More specifically, this study entails an application of a multidimensional Rasch Model for the purpose of (a) exploring the dimensional structure of the GSAS, (b) documenting the quality of the measures of the GSAS, and (c) examining the Differential Item Functioning (DIF) of the GSAS.

\section{Data and Method}

\section{Participants}

The sampling frame for this study was all degree-seeking graduate students at a research extensive public university in the Northeast who were enrolled during spring semester $2006(\mathrm{~N}=4,698)$. Fifty percent of the students responded to the web-based survey $(n=2,373)$, and respondent demographics closely match those of the target population, suggesting that a representative sample was achieved (Henderson \& Stassen, 2006). Fifty-four percent of the respondents were White; 4.6\% African/African American; 3.9\% Hispanic; 18.1\% Asian/Asian American; less than 1\% Native American; 3.5\% multiracial; and 15\% did not indicate ethnicity. Forty percent of the respondents were female, $37 \%$ male and $23 \%$ did not indicate gender. The disciplines represented in the study included the following: education, engineering, humanities and fine arts, natural resources and the environment, natural science and mathematics, public health, sociological and behavioral science, and the school of management. Forty-five percent of the respondents were pursing doctorate degrees, $33 \%$ were pursing master's degrees, and 22\% were pursuing other post-graduate degrees or did not indicate the degree sought.

\section{Instrument}

The GSAS consisted of 46 items that address six categories of advising: Criteria for Selection of Advisor (8 items), Functions of Advisor (16 items), Satisfaction with Advisor (7 items), Perception of Departmental Climate (6 items), Time to Degree (4 items), and Peer Influence (5 items). Although on this instrument the term that was used was primary advisor (PA), this term included persons who served as dissertation chairs, or major professors for doctoral students or as thesis advisor for master's students.

Demographic items - race and gender - were also on the survey. Several types of rating scale response options were used in the survey. These include agree/disagree, not a reason/minor reason/major reason, satisfied/not satisfied, helpful/not helpful, most of them/none of them options, as well as open-ended responses. The survey was developed by the Office of Academic Planning and Assessment (OAPA) and the Student Assessment, Research and Evaluation Office (SAREO), in consultation with representatives from the Graduate School, the Office of Institutional Research, and faculty from the Department of Educational Policy, Research, and Administration (EPRA) in the School of Education. The survey developers used the literature on advising to develop the instrument as well as consulted previous surveys on graduate education that contained subscales on students' advising experiences.

\section{Procedures}

The GSAS was administered by SAREO during April, 2006, using Sensus, a technically sophisticated web survey software program. The entire population of University graduate students was sent an email message to their University-provided email account inviting them to participate in 
the survey. This message, which contained a link to the survey, explained the purpose of the research and ensured confidentiality. Three follow-up email messages were sent to nonrespondents, and reminder phone calls were made to all graduate students with working telephone numbers.

\section{Analysis}

\section{Model}

Data were scaled with the Multidimensional Random Coefficients Multinomial Logit Model (MRCMLM) (Adams, Wilson, \& Wang, 1997), a multidimensional extension of the Rasch measurement model (Rasch, 1980), as implemented in the Conquest computer program (Wu, Adams, $\&$ Wilson, 1998). In this model, the GSAS measures multiple constructs that are correlated beyond trivial levels with only a few items on some of the subscales. Using the estimation of parameters via the MRCMLM allows for an increase in reliability over separate analyses by taking into account the correlation between the latent dimensions contained in these data (Briggs \& Wilson, 2003). The program utilizes marginal maximum likelihood to estimate $\gamma$, the matrix of regression coefficients, $\Sigma$, the variance-covariance matrix, and $\xi$, the item parameter vector of the MRCMLM. The fit of the model is ascertained by generalizations of the Wright and Masters (1982) residual-based methods that were developed by Wu (1997), using the deviance statistic. This program formally checks the model fit by alternatively positing dimensionality structures and comparing the fit between the latent construct and the observed score of these nonlinear models.

Three different relevant dimensional structures were considered to determine which of these dimensional configurations best represents the relationships in the observed data. Specifically, we examined a six-dimensional model utilizing the categories of items identified by the authors of the questionnaire, a two-dimensional model that compared negative worded items with the positive word items, and a unidimensional model. The relative fit of the data to each of these models was evaluated using the Schwartz's Bayesian Information Criterion (BIC) and the Akaike Information Criterion (AIC). Both of these statistics transform the deviance statistic $\left(G^{2}\right)$ by imposing a correction that takes into account the number of parameters estimated for the model in question. The BIC penalizes free parameters more strongly than does the frequently-cited Akaike information criterion. Generally, smaller values of AIC and BIC indicate a better fit of the data to the model.

\section{Instrument Psychometric Qualities}

Additional analyses focused on the psychometric qualities of the resulting measures.

Specifically, we examined the reliability of separation indices, the correlations between the latent factors, the polychoric correlation associated with each item within the six factors, and mean squared item fit indices.

\section{Differential Item Functioning}

We also evaluated the measures for differential item functioning (DIF). That is, we sought to determine whether respondents in different demographic groups who have comparable measures on the survey instrument have different probabilities of answering a particular item in a certain way. Evidence of differential item functioning was inspected for three groupings. The first was by degree level: doctoral level students and master's level students. The second was by academic discipline. Using the academic discipline classification model developed by Biglan (1973a, 1973b), the disciplines were divided into four different groups: hard/pure, hard/applied, soft/pure, and 
soft/applied. According to Biglan, academic disciplines can be divided into hard versus soft and pure versus applied dimensions. Disciplines that fall along the hard dimension (e.g., chemistry) are characterized as having a single paradigm, which makes them more prone to have consensus about content and methodology. Conversely, disciplines that fall along the soft dimension (e.g., education) are characterized as being non-paradigmatic and, as a result, are less likely to have consensus about content and methodology. Disciplines that fall along the pure dimension are characterized as being concerned with the building of theory (e.g., mathematics), whereas those positioned along the applied dimension (e.g., finance) are most concerned with applying theory. In this study, Natural Science and Mathematics comprised the hard/pure category. Natural Resources and Environment and Engineering comprised the hard/applied category. Humanities and Fine Arts, and Social and Behavioral Science comprised the soft/pure category. Finally, Education and Business comprised the soft/applied category. The final DIF investigation was completed using gender.

The investigation was completed by adding a group-by-item interaction term to the MRCMLM as implemented in the Acer Conquest (Wu et al., 1998) software and determining whether these interaction terms deviate from zero by a statistically significant amount (i.e., dividing the interaction term by its degrees of freedom to create a Wald t-statistic). Absolute differences greater than 1.96 were flagged as displaying DIF. Additionally, the magnitude of DIF was determined by examining the differences (doubled) in the group-by-item interaction parameter estimates. The effect of DIF was classified in three ways using this difference as a gauge (Wilson, 2005): substantial, if the difference $=0.64$ or greater; moderate, if the differences $=>0.43$ but $<0.64$; small, if the difference $=<0.43$. For this study, only items falling within the substantial DIF category were noted.

\section{Results}

\section{Model}

The three models compared in this study were 1) a unidimensional model, 2) a two-factor model that differentiated between positively- and negatively-polarized items, and 3) a six-factor multidimensional model that maintained the structure specified by the instrument developers. Based on the smaller values of each of the criterion statistics shown in Table 1, the results indicate that the six-dimensional model better describes the observed relationships than do the other two models. Specifically, the values of the AIC and BIC are smallest for this model. Thus, the remaining analyses focus on this six-dimensional model. The mapping of items onto the six-dimensional model is shown in the Appendix. It is interesting to note, however, that the two-dimensional model that differentiated between positively- and negatively-polarized items exhibited better fit than did the unidimensional model, suggesting that differential responses may have been made to these two types of items - differential responses that are not accounted for by the variability common to all items.

Table 1: Multidimensional Model Comparison

\begin{tabular}{cccccc}
\hline Factors & Deviance & Parameters & N & AIC & BIC \\
\hline 1 & 138218.91 & 128 & 1852 & 134770.91 & 132585.50 \\
2 & 133754.67 & 132 & 1852 & 133314.67 & 131134.33 \\
6 & 132909.37 & 150 & 1852 & 129505.37 & 127347.85 \\
\hline
\end{tabular}




\section{Instrument Psychometric Qualities}

\section{Reliability}

The reliability of separation values for the six subscales was computed as the Bayesian index described by Briggs and Wilson (2003). The results given in Table 2 show a range of reliability across the six factors from a low of .71 to a high of .85. These values are lower than found in some evaluation instruments but are within an acceptable range for a survey intended to ascertain opinions and perceptions.

Table 2: Reliability of Separation \& Latent Trait Correlations

\begin{tabular}{ccccccc}
\hline Dimension & 1 & 2 & 3 & 4 & 5 & 6 \\
\hline 1 & .71 & & & & & \\
2 & 0.61 & .85 & & & & \\
3 & 0.62 & 0.89 & .83 & & & \\
4 & 0.16 & 0.48 & 0.49 & .73 & & \\
5 & 0.46 & 0.86 & 0.84 & 0.65 & .79 & \\
6 & 0.36 & 0.59 & 0.59 & 0.82 & 0.76 & .76 \\
\hline
\end{tabular}

Note: Diagonal entries display the reliability of separation.

Off-diagonal entries display the disattenuated correlations between the latent traits.

\section{Correlations of measures}

Table 2 also displays the disattenuated correlations between the latent traits, which range from .16 to .89. The strongest disattenuated correlation was observed between Satisfaction with Advisor (Dimension 3) and Functions of Advisor (Dimension 2) (.89). This result is consistent with previous research, which shows that the more critical functions that an advisor fulfills, such as socializing their advisees to the discipline, networking their advisees with other professionals, and being accessible to their advisees, the more satisfied the advisee is with the relationship they have with their advisor (Lovitts, 2001; Nettles \& Millet, 2006). At the opposite end of the scale, Perception of Department Climate (Dimension 4) weakly correlated with Criteria for Selection of Advisor (Dimension 1) (.16). Again, this is consistent with our expectations because the bases on which students select their advisor probably has little to no bearing on how they perceive the overall climate of their department.

\section{Item quality}

As shown in Table 3, the polychoric correlations were all fairly high - the minimum value was .61 (Item 7). In addition, the mean-squared weighted item fit statistics tend to be in a range of acceptable values. The maximum value was 1.63 (Item 13).

Table 3: Item Quality Index Descriptive Statistics

\begin{tabular}{ccccc}
\hline Index & Mean & SD & Minimum & Maximum \\
\hline Polychoric Correlation & 0.75 & 0.07 & 0.61 & 0.91 \\
Mean Squared Weighted Fit & 1.01 & 0.20 & 0.56 & 1.63 \\
\hline
\end{tabular}

\section{Differential item functioning (DIF)}

DIF analyses were conducted only on data from respondents who answered at least four items. Surveys that did not meet this minimum were excluded, which resulted in some variation in sam- 
ple size. After application of the minimum number of responses criteria, the number of respondents remaining is shown in Table 4. Some respondents did not answer some of the demographic questions, also resulting in unequal total sample sizes across the various DIF comparisons.

Table 4: DIF Statistics Summary

\begin{tabular}{|c|c|c|c|c|}
\hline \multicolumn{5}{|c|}{ Discipline } \\
\hline Comparison & $\mathrm{N}$ & Mean $_{\mathrm{ES}}$ & $\mathrm{SD}_{\mathrm{ES}}$ & $\mathrm{N}_{\mathrm{ES}}$ Substantial \\
\hline Soft Applied vs. & 573 & 0.37 & 0.39 & 6 \\
\hline Hard Pure & 804 & & & \\
\hline Soft Applied vs. & 573 & 0.28 & 0.31 & 4 \\
\hline Hard Applied & 320 & & & \\
\hline Soft Applied vs. & 573 & 0.23 & 0.22 & 1 \\
\hline Soft Pure & 557 & & & \\
\hline \multicolumn{5}{|c|}{ Level } \\
\hline Comparison & $\mathrm{N}$ & Mean $_{\mathrm{ES}}$ & $\mathrm{SD}_{\mathrm{ES}}$ & $\mathrm{N}_{\mathrm{ES}}$ Substantial \\
\hline Master vs. & 786 & 0.28 & 0.25 & 5 \\
\hline Doctoral & 1066 & & & \\
\hline \multicolumn{5}{|c|}{ Gender } \\
\hline Comparison & $\mathrm{N}$ & Mean $_{\mathrm{ES}}$ & $\mathrm{SD}_{\mathrm{ES}}$ & $\mathrm{N}_{\mathrm{ES}}$ Substantial \\
\hline Male vs. & 867 & .012 & 0.09 & 0 \\
\hline Female & 941 & & & \\
\hline
\end{tabular}

The first discipline pairing was soft/applied versus hard/pure. There were six items that displayed DIF across these disciplines (Items 6, 7, 23, 25, 36, \& 41). Items 6 and item 7 were more easily endorsed by the respondents in the hard/pure fields than their peers in the soft/applied fields. We hypothesize that this observed difference arises because students in the soft/applied fields do not select their advisors based on the person's research interest nor do they expect their advisors' research projects to necessarily fund their graduate education. The third item that showed DIF between these two groups was item 25, which stated, "My primary advisor does not help me secure funding for my graduate studies" (reverse). Respondents in the hard/pure disciplines more easily endorsed that their primary advisor helped them secure funding than their peers in soft/applied disciplines. These differences make sense in light of the fact that many of the students who are in soft/applied fields, particularly education, do not receive any type of educational funding (Nettles $\&$ Millett, 2006).

Item 23, which states, "My primary advisor does NOT encourage me to publish" (reverse), was more easily endorsed by respondents in the hard/pure disciplines than it was for their peers in the soft/applied disciplines. Since many of the students who are in soft/applied fields are preparing to be practitioners instead of research scholars, having an extensive publication record is not usually required for post-doctoral placement. Therefore, publishing as a graduate student may not be an added pressure that advisors wish to place on their advisees. Item 36 also displayed DIF for the soft/applied and hard/pure grouping. In this case respondents in the soft/applied disciplines more easily endorsed this item, but once again it is not clear which one of the response categories they found most easy to endorse.

Item 41 also displayed DIF between students in the soft/applied disciplines and those in the hard/pure disciplines. This item asked respondents to "approximate the number of faculty in their academic program that seems more concerned with furthering their own careers than with the well being of the program as a whole." Respondents in the soft/applied disciplines more easily 
endorsed this item than their peers in the hard/pure disciplines, but similar to item 31 , due to the response categories - most, some, one or two, none - it is difficult to determine which particularly response category was most easily endorsed.

The second comparison for the discipline analyses, the soft/applied versus hard/applied groupings, revealed four items that displayed DIF (Items 6, 7, 25, \& 48). The first three of these items were also flagged for the previous comparison, and we believe that the same rationale applies to this comparison. The fourth item that displayed DIF was item 48, and it states, "Many students in my program complain of being exploited by the faculty." Respondents in the soft/applied disciplines more easily endorsed that students in their programs feel like they are being exploited than their peers in the hard/applied disciplines. This finding is quite surprising. Given that many graduate students who are pursuing graduate degrees in soft/applied disciplines generally do not serve as teaching assistants or research assistants as often as their peers who are pursuing degrees in the hard/applied disciplines (Nettles \& Millett, 2006), there does not seem to be a theoretical justification to explain these results.

For the final discipline grouping, soft/applied versus soft/pure, one item displayed DIF. That was item 6, which stated, "My primary advisor is doing research that interests me." Respondents in soft/pure disciplines more easily endorsed that they selected their primary advisor based on his/her research than their peers in the soft/applied disciplines. The difference in responses between these two groups seems reasonable since often students in the soft/pure disciplines have to identify someone who is doing research in the area in which they have an interest or they are not even admitted into the program. Conventional wisdom suggests this does not hold true for students in soft/applied fields such as education and business.

The second DIF category was degree level (master's \& doctoral), and these comparisons revealed four items with substantial DIF (items $6,42,43, \& 44$ ). Item 6 again appears displaying substantial DIF. As stated previously, that item asks the respondent to indicate the importance in the selection of the Primary Advisor based on the advisors' research "My primary advisor is doing research that interests me." Doctoral degree students endorsed this item more easily than master's degree students. Given the fact that many master's students do not engage in research as a part of their course of study, it seems reasonable that master's students would not select their advisor for research reasons. Additionally, a group of three items (item 42, item 43, item 44) were more easily endorsed by the master's students than the doctoral students. These three questions asked the respondent to estimate the proportion of faculty members in the academic program having been heard to "Make sexist remarks" (42), "Make racist remarks" (43), and "Make homophobic remarks" (44). As interesting as these findings could be, there are no theoretical or practical explanations to support these differences. However, given the importance for departments to create academically and socially welcoming environments for women, students of color, and gay/lesbian, and bisexual students, more research needs to be conducted in order to ascertain if, and why, students at the master's level could perceive difference in the departmental climate than their doctoral level peers.

The final DIF investigation looked at potential differences in responses between males and females. No items were found to display substantial DIF for the gender groups.

In all of these comparisons, it is important to note that the presence of DIF does not necessarily indicate that a particular item is biased, although it may be the initial step leading to that conclusion. Thus, these findings could provide enlightening information to the various departments with interest in improving the advising experience for both the advisor and advisee at the various degree levels. 


\section{Discussion}

This study examined the psychometric properties of the Graduate Student Advising Survey (GSAS) in an effort to validate its measures. The instrument was designed to measure various aspects of graduate students' experiences. The fit of a unidimensional, a two-factor, and a six-factor model were compared in order to determine which provided the best fitting model to the data. Statically, the six-dimensional model proved to be the best fitting solution. A six-dimensional model is also supported theoretically. For example, the literature on graduate education is replete with research that addresses advisor selection (Golde, 2006; Lovitts, 2001, 2004; Zhao, Golde, \& McCormick, 2007); the functions of graduate advisors (Barnes \& Austin, 2009; McClure, 1989; Schlosser, Knox, Moskovitz \& Hill, 2003; Winston \& Polkosnik, 1984); qualities of good and poor advisors (Barnes et al., 2010); advisor satisfaction (DeBord \& Millner, 1993; Lovitts, 2001, 2004; Nettles, 1990a, 1990b); and doctoral students time-to-degree (Baird, 1995; Bowen \& Rudenstine, 1992; Ferrer de Valero, 2001; Maher, Ford, \& Thompson, 2004; Nettles \& Millett, 2006).

Subscale reliabilities ranged from .71 to .85 , levels that are reasonable for research purposes. All items displayed acceptable point-polychoric correlations, suggesting that the items on the survey discriminated reasonably well. Similarly, item fit indices were also generally acceptable.

The subscale correlations were positive and moderate suggesting that each subscale measures a related, but not redundant, aspect of the advising experience. An important substantive interpretation of the results concerns the relationships among the subscales on the instrument. Specifically, the highest disattenuated correlation was observed between Functions of Advisor and Satisfaction with Advisor (.89). This is consistent with our substantive expectations because research shows that the more critical functions that an advisor fulfills, such as socializing their advisees to the discipline, networking their advisees with other professionals, and being accessible to their advisees, the more satisfied the advisee is with the relationship they have with their advisor (Lovitts, 2004; Nettles \& Millet, 2006). A second high disattenuated correlation was between Satisfaction with Advisor and Time to Degree (.86). The high correlations between these sets of subscales also have substantive meaning and are supported by previous research that suggests that advisors have an impact on students' time to degree (Ferrer de Valero, 2001; Maher et al., 2004). Lovitts (2001) determined from her research with high producing graduate advisors (those who graduate many Ph.D.s) and low producing advisors (those who produced few Ph.D.s) that high producing advisors had more interactions with their advisees, were more accessible, and collaborated more with their advisee than their low producing colleagues. Similarly, research has shown that there is a connection between how satisfied students are with their advising and the likelihood of them completing their degree (Girves \& Wemmerus, 1988). Conversely, Criteria for Selection of Advisor was weakly correlated with Perception of Climate (.14). Again, this is consistent with our substantive expectations because the bases on which students select their advisor probably has little to no bearing on how they perceive the overall climate of their department.

The DIF analyses suggest that the questions on the GSAS were appropriate for assessing various experiences of master's and doctoral students across disciplines and across gender with one possible exception. The one exception stems from the DIF that was identified between master's and doctoral students regarding perception of climate. Since there are no seemly theoretical rationale to justify why master's students would perceive their faculty to make more sexist, racist, and/or homophobic remarks than their doctoral peers, the differences that were found may lay in the way the questions were worded or the way the questions may have been interpreted. Therefore, departments who may be interested in assessing their departmental climate might what to think of a different way to ask those types of questions. 


\section{Limitation}

Although the results of this research suggest that the instrument evaluated in this paper is psychometrically sound, there are a few limitations to this study. First, the instrument was normed on students at a single institution; therefore, results may have differed if the if survey instrument had been distributed to doctoral students from across multiple institutions. Second, the instrument examined in this study coverer topics that typically go beyond the direct advisor-advisee relationship. Thus, departments or programs may not what to use the entire instrument if they are only interested in understanding their doctoral students advising experiences. Finally, this study is a U.S. based study. Faculty from other counties may not find these same topics to be of interest or of importance to the success of their doctoral students.

\section{Implications and Conclusion}

The findings from this study indicate that the GSAS is a psychometrically sound tool with satisfactory measurement characteristics including reliability; therefore, with the increasing call for programs and departments to assess what they are doing and how they are doing it in graduate education (Walker et al., 2008), this instrument can be used to assess master's and doctoral students experiences across disciplines. In addition, findings from this study can be used to stimulate conversation among students and faculty regarding advisor and advising expectations. Barnes (2010) suggested that advisor expectations influence doctoral students' persistence and success. Third, other graduate programs and departments can use or adapt the GSAS in an effort to survey their own graduate students about their advising experiences. Fourth, other campuses can use this study as a model for how to examine the psychometric properties of any instrument they use or develop in an effort to understand the experiences of their graduate students. Finally, the GSAS results may be used as a research tool to study graduate students' attitudes towards roles and responsibilities of graduate advisors.

Given the importance of doctoral advising, as well as the call to increase accountability for doctoral students' success, future research should investigate other aspects of the advising relationship such as the role advisors play in the socialization of their doctoral students. Future research should also examine the concepts explored in this study from the advisors' perspective. The advisor-advisee relationship is a didactic relationship. Therefore, in order for these relationships to be healthy and effective the perspectives of both the advisor and the advisee must be considered and adhered to.

\section{References}

Adams, R. J., Wilson, M., \& Wang, W.C. (1997). The multidimensional random coefficients multinomial logit model. Applied Psychological Measurement, 21, 1-23.

Austin, A. E. (2002). Preparing the next generation of faculty: Graduate school as socialization to academic career. Journal of Higher Education, 73(1), 94-122.

Baird, L. L. (1995). Helping graduate students: A graduate adviser's view. In A.S. Pruitt-Logan \& P. D. Isaac (Eds.), Student services for the changing graduate student population. New Directions for Student Services, No. 72. (pp. 25-32). San Francisco: Jossey-Bass.

Barnes, B. J. (2010). The nature of exemplary doctoral advisors' expectations and the ways they may influence doctoral persistence. Journal of College Student Retention: Research, Theory, and Practice, 11(3), 323-343.

Barnes, B. J., \& Austin, A. E. (2009). The role of doctoral advisors: A look at advising from the advisor's perspective. Innovative Higher Education, 33(5), 297-315. 
Barnes, B. J., Williams, E. A., \& Archer, S. A. (2010). Characteristics that matter most: Doctoral students' perceptions of positive and negative advisor attributes. NACADA Journal, 30(1), 34-46.

Biglan, A. (1973a). The characteristics of subject matter in different scientific areas. Journal of Applied Psychology, 57(3), 195-203.

Biglan, A. (1973b). Relationships between subject matter characteristics and the structure and output of university departments. Journal of Applied Psychology, 57(3), 204-213.

Bowen, W. G., \& Rudenstine, N. L. (1992). In pursuit of the Ph.D. Princeton, NJ: Princeton University Press.

Briggs, D. C., \& Wilson, M. (2003). Understanding Rasch measurement: An introduction to multidimensional measurement using Rasch models. Journal of Applied Measurement, 4(1), 87-100.

Cheatham, H. E., \& Phelps, C. E. (1995). Promoting the development of graduate students of color. In A. S. Pruitt \& P. D. Isaac (Eds.), Student services for the changing graduate student population. New Directions for Student Services. No. 72 (pp. 91-99).

Cornon, W. (2006). Getting ready to do history. In C. Golde \& G. Walker (Eds.), Envisioning the future of doctoral education: Preparing stewards of the disciplines. (pp. 327-349). San Francisco, CA: JosseyBass.

DeBord, L. W., \& Millner, S. M. (1993). Educational experiences of African American graduate students on a traditionally white campus: Succor, sociation, and success. Equity \& Excellence in Education, $26(1), 60-71$.

Denecke, D. D., Frasier, H. S., \& Redd, K. E. (2009). The Council of Graduate Schools' PhD completion project. In R. G. Ehrenberg \& C. V. Kuh (Eds.), Doctoral education and the faculty of the future (pp. 35-52). Ithaca, NY: Cornell University Press.

Ehrenberg, R. G., \& Kuh, C. V. (Eds.). (2009). Doctoral education and the faculty of the future. Ithaca, NY: Cornell University Press.

Etzkowitz, H., Kemelgor, C., \& Uzzi, B. (2000). Athena unbound: The advancement of women in science and technology. Cambridge, UK: Cambridge University Press.

Fagen, A. P., \& Suedkamp Wells, K. M. (2004). The 2000 National Doctoral Program Survey. In D. Wulff \& A. E. Austin (Eds.), Paths to the professoriate: Strategies for enriching the preparation of future faculty. (pp.74-91). San Francisco: Jossey-Bass.

Ferrer de Valero, Y. (2001). Departmental factors effecting time-to-degree and completion rates of doctoral students at one land grant research institution. Journal of Higher Education, 72(3), 341-367.

Girves, J. E., \& Wemmerus, V. (1988). Developing models of graduate student degree progress. Journal of Higher Education, 59(2), 163-189.

Golde, C. M. (1998). Beginning graduate school: Explaining first-year doctoral attrition. In M. S. Anderson (Ed.), The experience of being in graduate school: An exploration. New Directions for Higher Education, No.101 (pp.55-64). San Francisco: Jossey-Bass.

Golde, C. M. (2000). Should I stay or should I go? Student descriptions of the doctoral attrition process. Review of Higher Education, 23(4), 199-228.

Golde, C. M. (2006). Preparing stewards of the discipline. In C. Golde \& G. Walker (Eds.), Envisioning the future of doctoral education: Preparing stewards of the disciplines. (pp.3-20). San Francisco, CA: Jossey-Bass.

Golde, C. M., \& Dore, T. M. (2001). At cross purposes: What the experiences of doctoral students reveal about doctoral education. Retrieved December 16, 2010, from http://www.phd-survey.org

Hartnette, R. T., \& Katz, J. (1977). The education of graduate students. Journal of Higher Education, $48(6), 646-664$. 
Henderson, L. A., \& Stassen, M. L. A. (2006). The University of Massachusetts graduate student advising experience. Office of Academic Planning and Assessment, University of Massachusetts Amherst.

Hinchey, P., \& Kimmel, I. (2000). The graduate grind: A critical look at graduate education. New York, NY: Falmer Press.

Holland, J. W. (1998). Mentoring and the faculty development of African-American doctoral students. In H. T. Frierson, Jr. (Ed.), Diversity in Higher Education, Volume 2 (pp.17-40). Stamford, CT: JAI Press.

Jacks, P., Chubin, D. E., Porter, A. L., \& Connolly, T. (1983). The ABCs of ABDs: A study of incomplete doctorates. Improving College and University Teaching, 31(2), 74-81.

Knox, S., Schlosser. L. Z., Pruitt, N. T., \& Hill, C. E. (2006). A qualitative examination of graduate advising relationships: The advisor perspective. The Counseling Psychologist, 34(4), 489-518.

Lovitts, B. E. (2001). Leaving the ivory tower: The causes and consequences of departure from doctoral study. Lanham, MD: Rowman \& Littlefield.

Lovitts, B. E. (2004). Research on the structure and process of graduate education: Retaining students. In D. H. Wulff \& A. E. Austin (Eds.), Paths to the professoriate: Strategies for enriching the preparation of future faculty (pp. 115-136). San Francisco: Jossey-Bass.

Lyons, W., Scroggins, D., \& Rule, P. B. (1990). The mentor in graduate education. Studies in Higher Education, 1(3), 277-285.

Maher, M. A., Ford, M. E., \& Thompson, C. M. (2004). Degree process of women doctoral students: Factors that constrain, facilitate, and differentiate. The Review of Higher Education, 27(3), 385-408.

McLure, J. E. B. (1989 ). Recommendations for faculty advising. Ph.D. dissertation, Georgia State University, College of Education, Georgia, USA. Retrieved July 22, 2008 from Dissertations \& Theses: A\&I database. (Publication No. AAT 8922915).

Minor, J. T. (2003). For better or worse. Improving advising relationship between faculty and graduate students. In A. L. Green \& L. V. Scott (Eds.), Journey to the Ph.D. How to navigate the process as African Americans (pp. 239-253). Sterling, VA: Stylus Publication.

Nettles, M. T. (1990a). Black, Hispanic, and white doctoral students: Before, during and after enrolling in graduate school. (Graduate Record Examination Board Program). Princeton, NJ: Educational Testing Service.

Nettles, M. T. (1990b). Success in doctoral programs: Experiences of minority and white students. American Journal of Education, 98(4), 494-522.

Nettles, M. T., \& Millett, C. M. (2006). Three magic letters: Getting to Ph.D. Baltimore, MD: The Johns Hopkins University Press.

Rasch, G. (1980). Probabilistic models for some intelligence and attainment tests. Chicago, IL: University of Chicago.

Schlosser, L. Z, Knox, S., Moskovitz, A. R., \& Hill, C. E. (2003). A qualitative examination of graduate advising relationship: The advisee perspective. Journal of Counseling Psychology, 50(2) 178-188.

Walker, G. E., Golde, C. M., Jones, L., Bueschel, A. C., \& Hutchings, P. (2008). The formation of scholars: Rethinking doctoral education for the twenty-first century. San Francisco, CA: Jossey Bass.

Wilson, M. (2005). Constructing measure: An item response modeling approach. Mahwah, NJ: Lawrence Erlbaum Associates.

Winston, R. B., \& Polkosnik, M. C. (1984). Advising in graduate and professional school. In R. B. Winston, Jr., T. K. Miller, S. C. Ender, \& T. J. Crites (Eds.), Developmental academic advising (pp.287316). San Francisco: Jossey-Bass

Wright, B. D., \& Masters, G. N. (1982). Rating scale analysis. Chicago: MESA Press. 
Wu, M. L. (1997). The Development and application of a fit test for use with marginal maximum likelihood estimation and generalized item response models. (Unpublished master's thesis). University of Melbourne, Melbourne, Australia.

Wu, M. L., Adams, R. J., \& Wilson, M. R. (1998). ACER conquest generalized item response modeling software (Version 1.0) [computer program]. Melbourne, Victoria, Australia: Australian Council for Educational Research.

Zhao, C., Golde, C. M., \& McCormick, A. C. (2007). More than just a signature: How advisor choice and advisor behaviour affect student satisfaction. Journal of Further and Higher Education, 31(3), 263-281.

\section{Appendix}

\section{Dimension 1: Advisor Selection Criteria}

\section{Item Number}

\section{Item Text}

6 My primary advisor is doing research that interests me.

7 My primary advisor has a reputation for being able to fund graduate students.

$8 \quad$ My primary advisor was recommended to be by other people.

9 My primary advisor has a reputation for being a good advisor to graduate students

10 My primary advisor is well known in my discipline or field of study.

11 My primary advisor and I have a lot in common

12 My primary advisor has a reputation for getting graduate students through my program in a timely manner.

13 My primary advisor showed an interest in helping me succeed.

\section{Dimension 2: Function of Advisor}

20 My primary advisor is readily available to talk with me when needed.

21 When I first came to [University], my primary advisor helped me with the transition to graduate school.

22 My primary advisor treats me with respect.

23 My primary advisor does NOT encourage me to publish.

$24 \quad$ My primary advisor teaches me strategies for succeeding in my field.

25 My primary advisor does NOT help me secure funding for my graduate studies.

26 My primary advisor cares about me as a person.

27 My advisor helps me get to know other faculty members at the University.

28 My primary advisor helps me get to know other faculty or professionals in my field.

29 My primary advisor helps me navigate departmental politics.

30 My primary advisor initiates discussions about the progress I am making toward my degree.

31 My primary advisor is knowledgeable about formal degree requirements.

32 My primary advisor provides information about career paths open to me. 


\section{Item Number}

33

Item Number

(1)

(1)

\section{Item Text}

My primary advisor does NOT offer me encouragement.

My primary advisor gives me constructive feedback on my progress toward degree completion.

Overall, my primary advisor performs the advising role to my expectations.

\section{Dimension 3: Satisfaction with Advisor}

In general, how satisfied are you with your relationship with this faculty member?

I currently have the primary advisor I want.

There is another faculty member who I WISH were my primary advisor.

I am satisfied with the process by which I came to have my current primary advisor.

It was difficult for me to find a faculty member to be my primary advisor

I am satisfied with the amount of time I spend with my primary advisor.

I am satisfied with the quality of guidance I receive from my primary advisor.

\section{Dimension 4: Perceptions of Department Climate}

$\%$ of faculty who readily make themselves available to meet with graduate students

$\%$ of faculty who are conscientious about advising graduate students.

$\%$ who seem more concerned with furthering their own careers than with the well-being of the program as a whole.

$\%$ who make sexist remarks

$\%$ who make racist remarks

$\%$ who make homophobic remarks

\section{Dimension 5: Time to Degree}

Is the completion of your degree taking less time, more time, or about the time you expected?

How fully do you understand the formal requirements for successful completion of your program?

How helpful has your primary advisor been to you in terms of progressing toward the completion of your degree?

My academic program has structure in place to help graduate students make timely progress toward their degree.

\section{Dimension 6: Peer Influence}

\section{Item Text}

Graduate students in my program compete with one another for faculty time and attention. Experienced students in my program mentor new students.

Many students in my program complain of being exploited by the faculty.

Students in my program have an active role in program decisions that affect them.

Students freely share information with each other about how to get through the program. 


\section{Biographies}
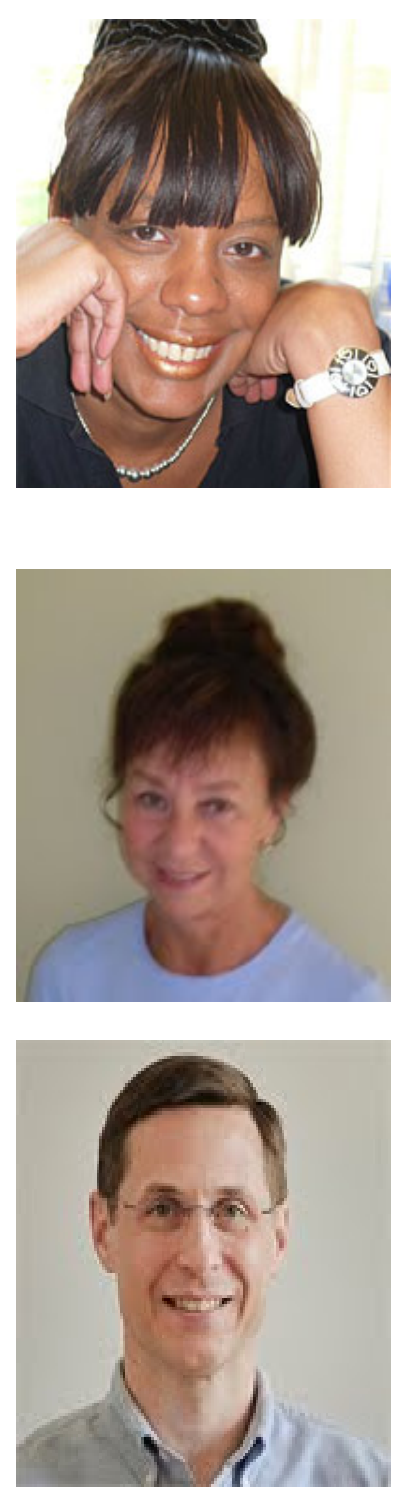

Benita J. Barnes, Ph.D., is an assistant professor at the University of Massachusetts Amherst in the department of Educational Policy, Research, and Administration. She holds her doctorate in Higher, Adult, and Lifelong Education from Michigan State University where she also earned a master's degree in Measurement and Quantitative Methods; a Master's degree in Adult and Continuing Education; and a B.A. degree in Psychology. Dr. Barnes's research includes graduate education, doctoral advising, and millennial students. Dr. Barnes is currently serving as concentration coordinator for the higher education administration program at UMass Amherst.

Linda Chard, Ph.D., holds her doctorate in Measurement and Quantitative Methods from Michigan State University. She also has an Educational Specialist degree from University of Michigan, a M.A. in mathematics from Indiana University, and a B.A. in mathematics and Spanish from Indiana State University. She retired from Educational Testing Service where she worked in psychometrics. Previously, she was an educator, serving as an administrator, teacher and instructor at the collegiate level. Dr. Chard's research centers on instrument construction with an emphasis on differential item functioning.

Edward W. Wolfe, Ph.D., is a Senior Research Scientist in the Assessment \& Information group of Pearson. In that position, Dr. Wolfe conducts research in support of test development and scoring. Dr. Wolfe's research focuses on applications of latent trait models to instrument development, the analysis of ratings, and computer-based testing. Dr. Wolfe received his Ph.D. in Educational Psychology with an emphasis in the areas of Psychometrics and Cognitive Science from the University of California at Berkeley in 1995. He received his M.S. in Educational Psychology from Purdue University in 1990, and he received his B.A. in Music/Education from Fairmont State College in 1987.

Martha L. A. Stassen, Ph.D., is the Director of the Office of Academic Planning and Assessment at the University of Massachusetts Amherst. Dr. Stassen's has published articles on faculty responses to racial and ethnic diversity, engaging faculty in learning assessment, and the student outcomes associated with living-learning community participation. She is also the lead author of two assessment handbooks used by a variety of higher education institutions across the United States. Dr. Stassen holds a B.A. in English (Music Minor) from Macalester College in St. Paul, Minnesota and a Ph.D. in Higher Education Administration from the University of Michigan, Ann Arbor. 


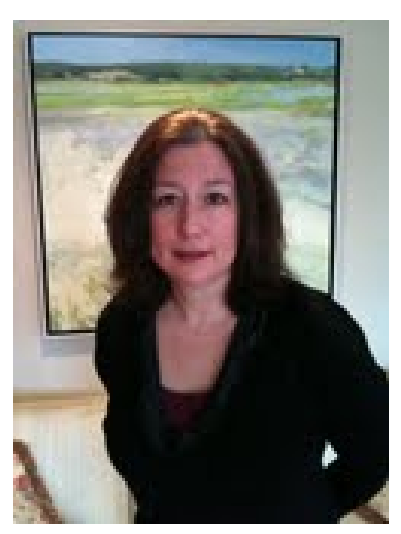

Elizabeth A. Williams, Ph.D. is Associate Director for Research in the Student Assessment, Research and Evaluation Office (SAREO) at the University of Massachusetts Amherst. She is also a faculty member in the department of Educational Policy, Research and Administration. She earned her master's degree and doctorate in Sociology at UMass Amherst, and a B.A. in Sociology and English from Connecticut College. Dr. Williams' most recent research projects have focused on the impact of lottery incentives on survey response rates, doctoral advising, and the prevalence of HSV-1 in a college student population. 